\section{PROCESSOS REFLEXIVOS: UMA EXPERIÊNCIA NA SAÚDE PÚBLICA EM MEIO À LUTA POR INCLUSÃO SOCIAL}

\author{
REFLEXIVE PROCESS: AN EXPERIENCE IN THE PUBLIC HEALTH IN \\ BETWEEN THE FIGHT FOR SOCIAL INCLUSION
}

RESUMO: Este trabalho tem como objetivo compartilhar a utilização da prática da equipe reflexiva, no âmbito da saúde mental, norteada pelos processos reflexivos desenvolvidos por meio das concepções do psiquiatra e terapeuta familiar norueguês Tom Andersen. Apresenta brevemente de que maneira esses aportes teóricos vêm influenciando a prática clínica da autora, relatando a seguir a história de Larissa, paciente que chegou para ser atendida no Centro de Atenção Psicossocial. Larissa denominou de "grande virada" o que ocorreu em sua vida após a conversa ocorrida com a presença de equipe reflexiva, da qual participaram a paciente e as duas equipes de cuidado designadas a ela (hospitalar e CAPS).

PALAVRAS-CHAVE: processos reflexivos; saúde mental; moradia.
ABSTRACT: This paper's objective is to share the usage of the practice of a reflective team, in the area of mental health, guided by the reflective processes developed through the conceptions of the norwegian psychiatrist and family therapist Tom Andersen. We propose a short introduction on the way those theorical inputs have influenced the author's clinical practice, reporting the following narrative about the patient Larissa who received care at the Psychosocial Care Center. Larissa named "the turning point" what happened in her life after the organized conversation based on the practice of a reflective team, of which the involved were the patient and two care groups designated to her (the hospital's and PSCC's).

KEYWORDS: reflective processes; mental health; housing.

\title{
INTRODUÇÃO
}

Durante minha Especialização em Terapia Familiar/Casal em um instituto localizado no interior do Estado de São Paulo, tive meu primeiro contato com a teoria que sustenta a utilização dos processos reflexivos desenvolvidos na equipe coordenada por Tom Andersen na Universidade de Tromso, Noruega, a partir de 1985 (Andersen, 1994; 1999). Vários atendimentos familiares foram realizados durante a minha formação e a cocriação de realidades alternativas inaugurou para mim novas perspectivas para um sistema terapêutico. Poder falar de uma forma não hierárquica, baseada em minhas afetações, já contaminada pela irreverência e a curiosidade despertadas anteriormente pelos trabalhos de Cecchin $(1987 ; 1998)$ foi, ao meu modo de ver, extremamente enriquecedor, não só para a prática profissional, como também para minha vida pessoal. 
Ao entrar em contato com o trabalho de Andersen, fui convidada a sair da perspectiva de um único ponto de vista "ou de determinada maneira... ou de outra" para a perspectiva inclusiva de "tanto... como" com o englobamento de diferentes vozes em um multiverso conversacional. Ao incluir a família para ouvir e ver as reflexões de uma parte do sistema terapêutico que assistira à conversa entre terapeuta e família, denominada Equipe Reflexiva, inaugura-se uma prática colaborativa sob premissas do construcionismo social. Não se trata de mais uma nova metodologia ou uma nova escola de terapia familiar e, sim, de uma fundamentação teórica que acompanhe o pensamento do terapeuta em todos os momentos. Aprender a trabalhar em colaboração conversacional com as famílias com destaque aos processos reflexivos e aos novos significados construídos, assim como no processo de questionamento motivado pela curiosidade da equipe como cenário generativo de mudanças, foi modificador dos meus valores, princípios e das minhas expectativas como terapeuta.

A voz de Andersen, bem como de outros parceiros teóricos da terapia colaborativa, cujas práticas cabem sob o guarda-chuva do construcionismo social (Rasera \& Japur, 2007), estabeleceu o norte em minha maneira de trabalhar, não somente como terapeuta familiar, mas no meu posicionamento para o diálogo em qualquer contexto profissional, seja ele em atendimentos individuais, familiares ou na coordenação de uma unidade de saúde mental.

A minha trajetória como terapeuta colaborativa passou por diversas mudanças, porém, acredito que a maior diferença foi me dar conta da polifonia que compõe cada pessoa, inclusive a mim mesma. Esse conceito bakhtinia- no, vindo de empréstimo da música, e que foi originariamente utilizado para investigar gêneros literários, a partir do romance polifônico criado por Dostoiévski, foi concebido a partir da percepção de que os personagens dentro da obra possuíam vozes de contextos sociais distintos e que, no todo textual, se apresentavam independentes uma das outras, constituindo o que Barros (1999) chamou de discurso poético, composto por sua complexidade e pelas múltiplas posições e contradições refratadas na obra dos conflitos sociais percebidos e retratados pelo autor russo.

Entendo a polifonia como uma multiplicidade de vozes das quais somos compostos, que se entrelaçam com interlocutores presentes ou personificados em nossos diálogos internos ou externos, em que todas são ouvidas e valorizadas enquanto vozes sociais, dentro de um contexto histórico cultural. Essas vozes apresentam posturas ideológicas diferentes entre si, algumas contraditórias. Entretanto, o que tornará uma voz mais forte e significativa em comparação a outras (ou até resultar em seu silenciamento, ao pensar o processo inverso) é a relação que estabelecemos com os muitos outros em nossa vida, tal como os contextos culturais, familiares, institucionais nos quais estamos inseridos. Esse processo, contudo, não é estático e imutável, pelo contrário, se encontra sempre em movimento e transformação. A cada novo encontro há uma nova possibilidade, há uma nova escolha, assim, o processo de constituição pessoal e relacional nunca é individual, mas sim um encontro de vozes e de sentidos sempre presentes nas relações humanas.

Tomar consciência deste coral polifônico de múltiplos conceitos, crenças e valores foi, de certa maneira, liber- 
tador. Ao ampliar a disponibilidade de vozes no campo de atendimento e oferecer diversas possibilidades, o terapeuta sai do topo da posição hierárquica - que tradicionalmente ocupa - para que se possa tornar mais uma voz entre tantas outras com as quais seu paciente entrará em contato. Atualmente, após dez anos da morte de Tom Andersen, tenho a oportunidade de olhar para minha prática e perceber de que maneira ela tem sido influenciada, durante todo esse tempo, pelo viés dos processos reflexivos desenvolvidos pelo autor, e permitir um deslocamento dessas práticas, de forma a desenvolver e ampliar ferramentas capazes de se encaixarem nos diversos contextos em que vivi.

Consideramos que os processos reflexivos são de grande relevância tanto no campo teórico quanto no campo clínico (Rasera \& Japur, 2007). Destaco, porém, sua importância no campo atual da saúde mental; utilizar esses processos pode significar que as vozes, normalmente silenciadas socialmente, possam ser escutadas e valorizadas.

Conforme me encantava cada vez mais com essa maneira de trabalhar, começava a vivenciar novas reflexões: como levar essa vivência de minha formação como terapeuta familiar para outros contextos de que participo? Como utilizar essas ferramentas para uma instituição de saúde mental sem ser incomum demais a ponto de provocar fechamento de possibilidades ao invés de novas aberturas?

\section{TRANSFORMAÇ̃̃ES NA ATUAÇÃO NO CAMPO DA SAÚDE MENTAL}

Há cerca de dez anos coordeno um Centro de Atenção Psicossocial (CAPS) para cuidado de pessoas em sofrimento psíquico, serviço de saúde integrante do SUS que atua objetivando viabilizar os princípios deste sistema, com garantia da universalidade, equidade, integralidade, despolarização do cuidado, com a participação democrática de todos os atores sociais envolvidos. Compete ainda ressaltar que os CAPSs são frutos da Reforma Psiquiátrica (RP) dos últimos trinta anos. Nasceram no Brasil, no caldo de cultura da reforma sanitária, da luta política contra a ditadura militar e do processo pela redemocratização do país, surgindo não apenas como um serviço, mas como uma estratégia produtora de uma ruptura com o modelo de assistência hegemônico manicomial. Trata-se de um dispositivo de cuidado com ações diversificadas elegendo o território como espaço de produção do cuidado, o que requer articulação intersetorial, tecendo uma rede com a atenção básica e com outros aparatos de saúde, construindo novas formas de sociabilidade e novos valores éticos. Não são apenas serviços substitutivos do modelo manicomial e sim centros de interação com a comunidade. Em seu cotidiano de cuidado é necessário pensar em um projeto terapêutico que leve em conta a singularidade e a complexidade de cada usuário. Além disso, contribui para uma mudança epistemológica do ato de cuidar, ressignificando o cuidado às pessoas para além de um diagnóstico, rompendo com o modelo médico centrado nas doenças e inaugurando uma relação diferente entre o sujeito que sofre e o cuidador (Yasui, 2006). Trata-se de um novo modo de pensar e lidar com a loucura, em que as pessoas em sofrimento mental possam ser cuidadas por práticas de reabilitação e não de internação, em que a moradia e o trabalho venham desencadear a transformação desse processo de tratamento. 
Entre os muitos desafios que a reforma psiquiátrica enfrenta no Brasil, e que não é o propósito deste artigo abordar, quero destacar as dificuldades do trabalho nos CAPSs, muitas vezes ainda guiados pelo modelo médico centrado na doença, apresentando como estratégia terapêutica primordial condutas medicamentosas. Mesmo dentro de um CAPS vemos sobreviver posturas asilares de isolamento, serviços trabalhando sem articulação com os outros, reproduzindo o modelo de poder/saber muitas vezes como privilégio das equipes, com discursos técnicos e monofônicos em que a razão se sobrepõe à loucura. Segundo Nunes, Guimarães e Sampaio (2016), o descompasso entre o modelo psicossocial e sua materialização ocorrem devido a múltiplos determinantes. Entre eles podemos citar o modelo de gestão atual, as dificuldades de financiamento, a não qualificação das equipes, a precarização do trabalho; esses fatores afetam diretamente as perspectivas e metas propostas para a saúde mental, muitas vezes resultando na opção por modelos que já se encontram mais reconhecidos historicamente enquanto "eficazes", justificando o fato de o hospital psiquiátrico ainda ser um recurso terapêutico tido como necessário e muito recorrente.

Outra problemática que tange o contexto atual da saúde mental diz respeito aos contatos entre o hospital psiquiátrico e o CAPS que são realizados pelo sistema de referência/contra-referência e ocorrem ainda hoje para encaminhamento dos pacientes. De acordo com tal sistema, o usuário atendido em um CAPS, quando necessário, é referenciado (encaminhado) para uma unidade de maior complexidade (hospital psiquiátrico), a fim de receber o atendimento de que necessita. Quando finalizado o aten- dimento, o mesmo deve ser contra-referenciado, ou seja, o profissional deve encaminhar o usuário para a unidade de origem (CAPS) para que a continuidade do atendimento seja feita. As informações contidas em ambos os encaminhamentos informam o diagnóstico, as medicações usadas, a sintomatologia psicopatológica presente, entre outras descrições empobrecidas sobre o contexto relacional envolvido em cada caso; discursos esses que legitimam e perpetuam uma forma de vida individualista, médico-centrada, com as instituições responsáveis pelo cuidado trabalhando de maneira independente e autônoma. Apesar de em alguns casos haver reuniões de serviços para discussão presencial dos casos que foram referenciados para uma internação integral, as mesmas acontecem na ausência do usuário e estão centradas nos discursos de déficits, focados nas doenças, diagnósticos e medicação, dando suporte a determinado vocabulário que, segundo Gergen (2010), tem contribuído muito para aquilo que podemos interpretar como fragilização social da nossa cultura, normalmente permeada de julgamentos de valores.

Para que ocorra a ruptura destas práticas (que aqui nomearei como manicomiais) e que seja possível o avanço da Reforma Psiquiátrica, torna-se necessário ousar e correr riscos, desconstruindo conceitos e inventando novas possibilidades. $\mathrm{Na}$ intenção de ampliar novas perspectivas, comecei a pensar na utilização dos processos reflexivos relacionada à minha atuação no contexto de saúde mental, e, nos últimos anos, fui capaz de perceber a presença da voz de Tom Andersen ativamente em minha prática. Neste trabalho, porém, selecionei o relato de um caso que foi excepcionalmente mobilizador para a pacien- 
te, para os participantes da equipe de cuidado e para outros órgãos sociais, o que resultou em transformações importantes no decorrer do tempo para o CAPS em questão.

Contar a história de Larissa ${ }^{1}$, a cliente em questão é, ao mesmo tempo, um desafio e um prazer. Estou chamando Larissa de cliente e não de paciente, pois, como será relatado a seguir, mesmo estando internada em um hospital psiquiátrico, a mesma já se encontrava em um processo ativo no atendimento, causando a mobilização de duas equipes de cuidado.

Tenho a percepção de que esta história não fala apenas de Larissa e, sim, da própria história da psiquiatria. Fala da psiquiatrização do social e do adoecimento de nossa cultura. Fala da necessidade de uma escuta mais ativa que possa facilitar o desenvolvimento de novas narrativas e, consequentemente, a construção de novas possibilidades. A aproximação do movimento construcionista social em relação à saúde mental tem ampliado diálogos para novas conformações de saberes e novas maneiras de trabalhar, oferecendo uma postura reflexiva na construção de práticas que privilegiam o foco no processo. Suas principais características são o destaque na linguagem, no contexto histórico social e na interação, ilustrando, assim, uma mudança paradigmática histórica na saúde mental. Sob esta perspectiva podemos descrever a doença como um fenômeno psicossocial, historicamente datado, sendo um parâmetro da ideologia vigente sobre o adoecer e ser doente mental em uma determinada cultura, sendo abordada não apenas como um fenômeno individual, mas como uma construção social em que a visão médica/psiquiátrica clássica deixa de ser o único olhar fidedigno, sendo legitimadas múltiplas visões, incluindo a do paciente que passa a ser o especialista da sua própria história (Anderson \& Goolishian, 1998). Ocorre um reposicionamento do diálogo do especialista para o campo polifônico onde outras formas de inteligibilidades possam ser construídas convidando ao surgimento de novas ações e à construção de diferentes mundos sociais.

Trata-se de uma transformação na esfera da saúde mental construindo, dessa forma, mudanças que possam facilitar o desfocamento do campo da doença para o da saúde, das deficiências para o das potencialidades, de uma visão reducionista para a complexidade, do lugar de paciente para ser agente da própria vida, do olhar da instituição para o do contexto social, entre tantas outras vicissitudes. Somente assim a instituição poderá sair do papel manicomial para um contexto social mais amplo, em direção à promoção da inter-relação CAPS/ comunidade, constituindo-se como a ferramenta precursora no processo de construção de um novo modelo de saúde mental.

É em meio a essa mudança constante de sentidos que o caso de Larissa se situa, realizado em um hospital psiquiátrico em que foram utilizados processos reflexivos e os futuros desdobramentos que vieram a se acumular no campo da Saúde Mental em nossa cidade.

\section{FALANDO DE LARISSA}

Larissa veio encaminhada ao CAPS em 2009, com 29 anos, após inúmeras internações (mais de 40), sendo a primeira aos 12 anos de idade, passando por diversos hospitais psiquiátricos. Antes de ser encaminhada ao CAPS, já realizava tratamento em outra unida-
${ }^{1}$ Com relação aos aspectos éticos, a paciente autorizou o uso de seus dados para a realização deste artigo. 0 nome fictício a ser utilizado, "Larissa", se trata de uma opção da própria paciente. 
de de saúde e, devido a uma mudança de endereço, nos foi encaminhada após uma internação recente.

Em um dos primeiros contatos com a unidade relatou morar com uma amiga desde que saiu de sua cidade natal e afirmou que gostaria muito de ter sua casa. Contou que na sua infância era quieta, tinha pouco contato com as pessoas e que, desde muito cedo, tomava remédio psiquiátrico. Trabalhava cuidando de crianças até ter sido internada por tentativa de suicídio por volta dos 20 anos de idade. Em sua tentativa, tomou diversos comprimidos e saiu desorientada pelas ruas, até que se sentou em uma ponte e acabou caindo lá de cima, o que resultou em diversas fraturas em seu corpo.

No CAPS, Larissa era descrita pela equipe como uma pessoa exigente e muito difícil, que apresentava pouca resistência à frustração e, sempre que contrariada, ameaçava se matar. Tal descrição, por ser compartilhada tanto pela equipe do CAPS quanto pela instituição onde a mesma frequentemente era internada, ganhava o status de verdade. Passou por várias internações psiquiátricas que, hoje em dia, descrevo como sociais, visto que eram realizadas em função de a paciente não ter onde morar. Isso ocorria pois, como não sabia utilizar o cartão do banco, fazer contas ou sacar dinheiro, acabava necessitando de uma pessoa para exercer a curatela da sua vida. Devido a isto, ficava - de certa maneira - prisioneira da vontade do outro. Quando brigavam, ficava sem ter onde morar e acabava sendo internada, repetindo este ciclo. Em 2011 esteve internada durante onze meses e saiu com indicação de ir para uma residência terapêutica. Essa era sua vida até aquele momento. Era internada cerca de uma ou duas vezes por ano, dependendo do período de internação.

\section{QUEBRANDO PROTOCOLOS E AMPLIANDO POSSIBILIDADES}

Durante a última internação psiquiátrica, em agosto de 2012, após três anos de tratamento no CAPS, sendo esta sua terceira internação durante este período, aconteceu um fato inédito. Ela conseguiu quebrar o protocolo da instituição em que estava e ligar para o CAPS para falar comigo. Larissa já estava internada há dois meses e encontrava-se muito hostil. Falava em colocar fogo na casa devido à dificuldade que estava apresentando de relacionamento e de moradia. O motivo da internação foi o risco de auto e heteroagressividade ${ }^{2}$. Anos mais tarde ela contou que havia solicitado várias vezes para ligar, o que não era permitido aos pacientes. Para que conseguisse realizar tal façanha, teve de ficar sentada durante dias atrás da janela que dava para o corredor, esperando a oportunidade de usar o telefone da unidade. Certo dia ouviu alguém dizer o número do telefone do CAPS e primeiro anotou com uma pedra na parede e, a seguir, passou com a própria pedra para um papel. Assim que surgiu uma oportunidade, escondida da equipe, resolveu telefonar.

Confesso que a minha primeira sensação ao receber o telefonema foi de perplexidade. Não era sua médica assistente e sim a coordenadora da unidade e, embora já tivesse conversado com ela diversas vezes, tinha a impressão de que não possuía vínculo suficiente para me ligar. No geral, mesmo na programação da alta, as conversas ocorrem entre as equipes. Por este motivo, a minha primeira reação em relação ao seu telefonema foi de questionar o porquê ela estaria me ligando. Por que não foi alguém da equipe? Fiquei na dúvida se deveria atender ou não. A curiosidade venceu a inércia. A 
irreverência venceu o protocolo. Atendi ao telefone. O pedido de Larissa que ecoou aos meus ouvidos e que com o tempo deu ressonância a inúmeras outras vozes foi o seguinte: "quando a senhora vai vir aqui para a gente decidir onde vou morar?".

Acostumada a olhar para Larissa dentro da sua "história dominante" (White, 2012) de doenças e sintomas, pude, neste momento, escutá-la em sua história periférica e que permeava todas as outras áreas de sua vida: a falta de moradia. Poder ouvi-la como uma pessoa desabrigada e não como uma pessoa doente ampliou o meu olhar e construiu novas possibilidades. Essa problemática social, conforme fui constatando no decorrer do tempo, era muito mais grave e incômoda para ela do que qualquer outro diagnóstico que pudesse vir a ter.

Marquei uma reunião no hospital, convidei uma enfermeira para ir comigo para termos uma conversa com Larissa junto com as duas equipes de cuidado. Hoje, olhando para esse episódio, após cinco anos do ocorrido, entro em contato novamente com o que Andersen (1998) chamou de "intuição": "Ao retraçar meus caminhos profissionais, minha intuição me diz que devo primeiro tomar parte, e então sentar e pensar a respeito deste tomar parte, e não pensar primeiro e só então tomar parte” (p. 70).

Acredito que foi o que eu fiz. Primeiro tomei parte e decidi ir ao hospital e só depois sentei e avaliei a minha ação. Senti-me muito confortável ao ter essa atitude. Minha intuição me dizia que era o melhor a fazer, já que Larissa era frequentemente internada e repetir as mesmas condutas de referência e contra-referência só iria culminar, em breve, em outra internação, ajudando a reafirmar cada vez mais a imagem de "incompetência no geren- ciamento de sua vida" que aqueles ao seu redor haviam ajudado a construir.

\section{CONVERSANDO NO HOSPITAL: A GRANDE VIRADA}

Quando resolvi fazer uma reunião no hospital envolvendo as duas equipes, me propus a trabalhar a partir dos processos reflexivos, rompendo com as burocracias e propondo um encontro de vozes sem hierarquias, onde a equipe e a cliente tivessem as mesmas possibilidades de enunciação e escuta. No entanto, sabia que nenhum dos envolvidos tinha noção do formato que iríamos trabalhar e que, ao utilizar essa proposta, deveríamos nos afastar dos vocabulários que os membros da equipe normalmente usam para fazer referência aos clientes na ausência deles, e nos aproximar do que Andersen (1999) definiu enquanto uma linguagem mais cuidadosa e com menos julgamentos valorativos.

Larissa encontrava-se internada há dois meses e não queria mais retornar para o local em que morava, deixando a equipe hospitalar sem saber o que fazer, pois se encontrava em condições de alta e não tinha para onde ir. A reunião foi desencadeada pela iniciativa da cliente, o que causou inicialmente mal-estar entre as equipes, mal-estar esse coerente dentro de um paradigma manicomial em que a voz do outro deve ser suprimida: os atos de cuidado devem ser solicitados pelas equipes e não pelos pacientes, principalmente quando se trata de articulações entre serviços. Além disso, a relação entre Larissa e as equipes carregava conflitos anteriores, pois, como já citado neste artigo, quando contrariada Larissa ameaçava se matar, o que deixava as equipes reféns, sem saber como se posicionar e agir diante dessa atitude. 
Suas condutas provocavam reações e ações contraditórias nas equipes de cuidado: enquanto alguns membros achavam que ela deveria ter alta, muitos acreditavam que ela deveria continuar institucionalizada e outros a adotaram e se propunham a assumir seu cuidado mesmo fora da instituição. É possível perceber, nessas situações, certo despreparo dos funcionários, tal como apontaram Nunes, Guimarães e Sampaio (2016), retratando a formação inicial precária e um não apoio dentro dos campos de atendimento. Acredito que tal descompasso poderia ser suprido se tivéssemos em nossas instituições programas de educação permanente, e não apenas programas pontuais de educação continuada. Torna-se de suma importância que os cotidianos de trabalho em equipe possam ser ordenados pela noção de aprender a aprender, em que a saúde e a educação caminhem de mãos dadas, produzindo uma atenção integral e humanizada.

Chegamos para a conversa no hospital em uma tarde extremamente quente, na véspera de um feriado prolongado. Enquanto dirigia para o hospital, ficava me questionando o que havia neste convite de Larissa que me impactara tanto.

Após uma conversa inicial entre os membros das duas equipes, sendo cinco técnicos do hospital e dois do CAPS, decidimos conversar com Larissa, que aguardava muito ansiosa por esta reunião. Propus que esta conversa pudesse ocorrer nos moldes da equipe reflexiva proposta por Andersen (1999), com duas de nós no campo. As outras participantes ficariam em um lugar de reflexão e em determinado momento teriam voz para falar. Como se tratava de um modelo de atendimento ainda desconhecido das equipes, em determinados momentos durante a conversa do campo com a Larissa fomos interrompidas, porém, todas as interrupções acabaram sendo úteis para o processo.

Iniciamos a conversa com Larissa perguntando qual seria o pedido dela para esta reunião e quais as suas expectativas em relação a este encontro. Larissa respondeu que não deseja voltar para casa e morar com a amiga e citou vários motivos pelos quais se recusava a retornar. No entanto, quando lhe foi oferecida a possibilidade de morar só ou em uma pensão, recusou a oferta dizendo que não daria conta, que tinha muito medo de ficar só.

À medida que a conversa seguiu Larissa continua falando que a amiga controlava sua vida e que muitas vezes lhe dizia para não ir ao CAPS e que, para evitar brigas, ela acabava obedecendo. Em outros momentos falou que a amiga queria levá-la para baladas, não queria que ela tomasse os remédios para fazer uso de bebidas, porém Larissa recusava a oferta. Além disso, Larissa se queixava de ter medo de dormir sozinha, sendo este um dos motivos que a impediam de morar só. Relatou, contudo, que quando a amiga ia para as baladas, ficava só a noite toda. Neste momento, pontuei que ela também sabia "dizer não" para a amiga, e que, dessa forma, quando a mesma solicitasse que deixasse de ir ao CAPS, tinha a possibilidade de "desobedecê-la", da mesma forma que o fazia quando se recusava a participar das baladas.

Foi possível perceber, em sua fala, essa contradição e, conforme tentava expor a ela que apesar de ter medo de ficar/dormir sozinha ela, ao mesmo tempo, conseguia superar esse medo, vide as diversas noites em que a amiga saia. Essa foi uma tentativa de, aos poucos, convidá-la a se agenciar por suas ações e, como resposta, Larissa 
ampliava seu discurso, tornando a falar de suas "incapacidades" que impediam sua autonomia para morar sozinha. Talvez essa reação tenha se dado pela estranheza de encarar suas "incapacidades” e gerenciar suas ações, visto que, até então, Larissa sempre havia ocupado uma posição passiva, um rótulo de alguém que sempre precisava ser "cuidada". Dessa forma, ela falava da dificuldade de controlar sozinha todas as contas, que não conseguia se organizar sem ajuda. Durante muito tempo focou sua fala apenas nas coisas que não conseguia fazer. Nesse momento, a equipe reflexiva, mesmo sem ser solicitada, como um coral de múltiplas vozes em uníssono, começou a pontuar as coisas que Larissa conseguia fazer: realizar anotações de receitas que assiste em programas de televisão, jogar dominó, ajudar no cuidado com outras pacientes, entre outras habilidades que, por parecerem pequenas e cotidianas, são facilmente esquecidas quando se ocupa o rótulo de "incapaz". Motivada pela equipe reflexiva, Larissa alterou seu discurso e começou a falar que sabe cuidar de uma casa e cozinhar, só que no tempo dela, e que a amiga não aceitava seu ritmo e acabava a atrapalhando muito.

A conversa seguiu durante um bom tempo com Larissa narrando as dificuldades em morar com a amiga. Por este motivo, a questionamos uma vez mais: ela conseguia enxergar alguma possibilidade de continuar morando junto à amiga? Como a resposta foi negativa, disse-lhe que deveríamos então começar a pensar em alguma saída a partir desse ponto. Fiz-lhe outra pergunta, dessa vez mais grave: se gostaria de continuar morando no hospital e, dessa forma, abrir mão de sua liberdade. Larissa disse não querer morar no hospital e que queria sair imediatamente. Narrou sua experiência e disse que era vítima das ações do hospital, visto que a instituição não se importava com o que aconteceria a ela, que podiam "tacá-la" onde for que "tanto fazia". Nesse momento questionei essa sensação de descaso, pois se a instituição realmente não acreditasse que haveria alguma diferença no local em que ela seria destinada, não teria sentido a organização da reunião e da conversa que estávamos a realizar. Neste momento, Larissa permaneceu em silêncio, reflexiva sobre o apontamento.

A equipe tornou a fazer algumas reflexões na tentativa de mostrar à Larissa os lados bons da instituição em seu cuidado e também as possíveis dificuldades que encontraria fora da mesma. Um dos membros da equipe interrompeu nesse tópico e disse que Larissa precisava ter força de vontade para realizar suas coisas, caso contrário, todo o trabalho realizado pelos funcionários seria inútil. Esta frase pareceu "agredir" Larissa, pois a mesma pareceu interpretá-la como uma forma de responsabilização individual por suas dificuldades como se todo peso do mundo estivesse em seus ombros. Por esse motivo, se tornou muito defensiva e agressiva, e respondeu ao funcionário que este apenas falava assim porque nunca teve que passar pelo o que ela teve que viver. Novamente, achei importante chamar sua atenção, para que pudéssemos, juntas, continuar a conversa, mas, da mesma forma que respondeu ao outro membro, agressivamente, repetiu dizendo-me que eu também não havia vivido suas experiências. Respondi-lhe que o contrário também é verdade, que ela não conhecia minha história e que, por este motivo, esse tipo de afirmação defensiva que ela levantava se tornava muito complicada, visto que todas as pessoas passam por dificuldades na vida. Larissa, então, começou a expor 
suas experiências, em especial a relação com sua mãe: disse-me que eu não tive uma mãe como a dela, perguntou-me se eu já havia apanhado de pau e, antes mesmo de ouvir minha resposta, mostrou-me a cicatriz que possui no rosto; enquanto chorava, disse que sua mãe tentou matá-la com uma panela de pressão. Larissa estava em prantos e nos questionava: "que tipo de mãe faz isto?".

Um grande silêncio permeou nossa conversa naquele momento, sendo interrompido apenas pelos soluços de Larissa. Passado um tempo, segui com a conversa e the disse, com calma, que devia ser muito ruim termos uma mãe que tenta nos matar, mas que, a meu ver, suas atitudes, como seus atentados contra a própria vida, eram bem semelhantes das de sua mãe. Disse-lhe que uma mãe que tenta nos matar é ruim, mas que me parecia ainda pior vê-la tomar as mesmas atitudes e voltar-se contra si mesma, pois quando crescemos temos a possibilidade de nos afastar de nossos pais, como havia sido a escolha dela, entretanto, não temos como nos afastar de nós mesmos.

De acordo com Andersen (2004), algumas palavras tocam intensamente aquele que fala. Quando ofereci à Larissa a minha reflexão, já havia sido tocada profundamente por sua dor, raiva e abandono, porém, mais do que isso, ao descrever o quanto ela mesma se abandonava, forneci para Larissa uma voz mais ativa naquele momen-

${ }^{3}$ Amorim (2012), ao discutir os conceitos de cronotopia e exotopia em Bakhtin, afirma que "ninguém é herói de sua própria vida” (p. 97), que o outro é capaz de sempre me ver com um pano de fundo que me foge à visão, um horizonte social que me é inacessível, e o inverso também acontece: sou capaz de ver no outro algo que ele

não vê. revelando a mim e aos outros membros da equipe aspectos de nossos atos e discursos que a nós não eram visíveis). Para isso foi preciso me colocar em seu lugar, entender a sua dor e seu contexto de vida (sem me confundir com eles) para, posteriormente, voltar ao meu lugar de terapeuta. Nessa ação revelei, através de minhas palavras, que $\mathrm{o}$ ato de abandonar também depende dela, porém, de uma forma diferente da maneira que um dos participantes pontuou. Sua voz, sua experiência de vida precisam ser valorizadas; ela precisa ser reconhecida. A violência que Larissa sofreu foi um elemento constitutivo do lugar em que ela se encontrava, ou seja, sua mãe (mas não somente esta) participou ativamente na construção do rótulo da "pessoa que não consegue dar conta da própria vida", mas, simultaneamente, tentei mostrar que ela também possuiu responsabilidade para que isso acontecesse. Procurei, dessa forma, não posicioná-la como a única responsável por suas escolhas e, assim, acolher e compreender sua dor. A partir da posição que ocupava, intencionei dar um acabamento estético (Bakhtin, 2011) para Larissa, consciente de que apenas se minha voz for suficientemente significante é que causarei algum impacto nela, possibilitando transformações. Naquele momento, recordei-me da voz de Andersen (2004), ao dizer que as palavras não são inocentes:

A linguagem e as palavras são como mãos que buscam algo; poderíamos dizer que a linguagem é um órgão do sentido. Mas as palavras são mais do que isso. Como uma mãe que agarra e segura, as palavras captam e guardam os significados. Assim, [as palavras influenciam] os significados a que chegamos. As palavras não são inocentes. (p. 23) 
Apesar das lágrimas, Larissa foi ficando mais tranquila. No entanto, ao terminar de chorar, pareceu retornar ao seu padrão de funcionamento anterior, assumiu novamente o "abandono"; voltou a falar que ninguém ali estava interessado nela. Perguntei-lhe, então, por que ela imaginava que estávamos passando a tarde toda ali, em um calor horrível, nas vésperas de um feriado prolongado. Ela argumentou que estávamos ali apenas porque aquele era o nosso trabalho. Falamos que poderíamos simplesmente não ter ido. A equipe - novamente em coro - complementou que poucos fariam isso. Larissa, entretanto, retornou a falar que as pessoas a abandonam: citou o médico com quem havia tentado conversar no hospital e que havia se negado a ouvi-la; citou funcionários do CAPS que não apresentaram disponibilidade quando ela os chamou para conversar; por fim, disse que tentou falar comigo diversas vezes, mas que, entretanto eu me encontrava ocupada demais para ouvi-la.

Em resposta, disse-lhe que não é exatamente fácil relacionar-se com ela, e que, apesar disso, muitas vezes sentamos no CAPS para conversarmos; que já havíamos nos reunido para fazer seu currículo; que, em certa festa junina, ajudei-a a maquiar-se. Apesar de todas as vivências juntas, tentei lhe explicar que, no cotidiano da instituição, nem sempre é possível parar o trabalho/atividade para um momento de conversa. Além disso, disse-lhe que podemos dar atenção a ela dez vezes, mas se recusarmos uma única vez ela acabará ficando com muita raiva e não valorizará às vezes anteriores, o que tornará a relação com ela bastante difícil e instável.

Em especial, porque quando Larissa fica com raiva, acaba ameaçando a equipe e até sua própria vida, causan- do um grande mal-estar da equipe em relação a ela. Neste momento todos os presentes compartilharam desse meu sentimento e ainda afirmaram que quando ela agia desse jeito, parecia que estava "abandonando" a relação que já estabelecera com a equipe, além de sentirem certa raiva pela grande quantidade de ameaças recebidas.

A partir destas reflexões, que fizeram coro na voz da equipe reflexiva, a conversa foi ficando muito mais leve e pudemos propor para Larissa a possibilidade de que ela viesse a tentar morar em uma pensão, e que, inicialmente, uma das funcionárias do hospital, que a conhecia desde menina, iria cuidar do seu dinheiro, até que ela conseguisse dar conta sozinha. Larissa aceitou a proposta e se despediu de nós nos agradecendo muito. Posteriormente, veio a denominar essa conversa de "A Grande Virada" de sua vida.

\section{TOMANDO NOVOS CAMINHOS}

Ao sair do hospital, dois dias após a conversa, Larissa foi morar em uma pensão, cuja dona era mãe de outra paciente que frequentava o CAPS. Durante estes últimos cinco anos (2012-2017) não foi internada. Como combinado durante a conversa, uma funcionária do hospital cuidou de seu dinheiro por cerca de um ano. Enquanto isso dois funcionários do CAPS se empenharam a ajudá-la a aprender a fazer as contas necessárias em seu dia a dia. Uma acompanhante terapêutica voluntária começou a acompanhá-la nas idas ao banco, para que pudesse ensiná-la a usar o caixa eletrônico.

Nunca mais ameaçou com palavras ou com ações a própria vida. Quando a promotoria determinou que ela fosse morar em uma residência terapêutica, Larissa nos procurou para saber o que

\section{1}


ganharia e o que perderia com esta escolha. Pediu um tempo para conversar com seus colegas do CAPS e quando voltou disse que não precisava de uma residência terapêutica e, sim, de uma residência que fosse sua. Recusou a oferta e continuou pagando o aluguel da pensão.

Atualmente Larissa coordena o caixa de uma oficina de economia solidária, função essa que muito a ajudou a desenvolver lados mais saudáveis da sua vida, além de possibilitar que pague parte do aluguel. Encontra-se há três anos morando junto com seu companheiro, que conheceu em umas das feiras de arte e artesanato em que o CAPS participou e continua lutando para ter sua casa.

\section{ALÇANDO NOVOS VOOS}

Em 2014 o CAPS recebeu a visita, para uma breve interlocução, de um psiquiatra e pesquisador italiano, o Dr. Ernesto Venturini. Vindo para o Congresso Internacional de Saúde Mental, este nos concedeu a honra de sua presença. Vários profissionais de diversas áreas participaram desse encontro, assim como alguns usuários do CAPS, entre eles, Larissa. Tínhamos na época várias ideias e questões para discutirmos, no entanto, assim que iniciamos nossa conversa, Larissa se apresentou e disse que não tinha casa. Dr. Venturini imediatamente perguntou para os participantes quem tinha onde morar e disse ser muito bom poder ter um lugar para poder voltar. A seguir questionou se a moradia não fazia parte do projeto terapêutico do CAPS, pois não é possível termos um bom projeto terapêutico se a moradia (se um "após") não for incluída.

A partir deste questionamento, já antes tocados pela luta de Larissa, vários espaços e instituições sociais acabaram sendo mobilizadas, o que nos estimulou a fazer um projeto intitulado "Mutirão Solidário". Tal projeto foi, posteriormente, apresentado no Fórum de Saúde Mental e tem articulado a rede intersetorial na tentativa de conseguirmos moradias para os usuários da saúde mental. Contar sobre essas atividades com certeza seria outro trabalho. Larissa tornou-se a porta-voz desta luta, participando ativamente do fórum em busca de um lugar para morar.

\section{REFLEXÕES SOBRE 0 ATENDIMENTO: CONSIDERAÇÕES FINAIS}

Conforme comecei a escrever sobre este estudo de caso, passei a sentir-me mobilizada com a polifonia despertada pelo mesmo e das inúmeras vozes presentes nesta narrativa. A voz de Larissa soa para mim como o pano de fundo deste trabalho, tornando presentes inúmeras outras. Durante essa trajetória entrei em contato com várias inteligibilidades, muitas vezes competitivas entre si, em que essa história encontra-se inserida. Considero o discurso manicomial ainda como uma voz e sentido hegemônicos dentro do processo histórico de trinta anos de uma reforma psiquiátrica inacabada e ameaçada. Quando Larissa foi internada pela primeira vez, aos 12 anos (1992), o manicômio ainda era a alternativa quase inquestionável para as pessoas descritas como doentes mentais. Atualmente o discurso da Reforma Psiquiátrica (RP) compete com o manicomial abrindo diversas portas, porém, mesmo assim, Larissa continuou a ser internada no decorrer de todos esses anos.

A história de Larissa nos convida a pensar em um cenário colaborativo 
para a saúde mental, abrindo diálogos mais constantes entre as instituições e as mesmas com seus usuários, de forma a ampliar espaços para outra voz, outra visão, outra maneira de trabalhar que privilegiem as relações como fontes de significados, suplementando nossas tradições individualistas e hierárquicas de cuidado.

A atitude de sair de um CAPS e propor uma conversa utilizando os processos reflexivos provoca, de certa forma, a perturbação das fronteiras entre os serviços e é estabelecido um diálogo entre tradições muito diferentes. Entretanto, embora a própria equipe hospitalar compartilhe com o discurso da RP, ainda se faz presente uma tensão muito grande entre práticas e discursos tão divergentes e, por vezes, até contraditórios. Ao quebrar o isolamento entre os serviços e introduzir os processos reflexivos para a discussão do caso clínico em questão, no interior de um hospital psiquiátrico, abre-se um convite para reformular formas de se pensar e atuar dentro do contexto das atuais políticas públicas em saúde mental.

Nesse sentido, o caso de Larissa nos permitiu perceber a importância e a força de discursos hegemônicos que perpassam nossas narrativas de vida; tal como apontaram White e Epston (1990), as experiências narradas nunca conseguem expor a completude/ totalidade daquilo que o sujeito efetivamente viveu, ou seja, muitos aspectos são deixados de fora quando contamos uma história, principalmente quando esta se encontra em descordo com outros temas ou enredos dominantes de nossa vida. Apenas quando compreendemos a linguagem em seu caráter performático, isto é, enquanto uma prática social em que discursos diferentes constroem realidades distintas, em que a linguagem se torna constitutiva da vida de seus sujeitos, é que podemos perceber e propiciar situações favoráveis para a constituição de novas experiências que permitam o desenvolvimento de narrativas alternativas.

Para refletirmos sobre esta questão, trago alguns exemplos, tanto em relação às mudanças de narrativas da própria autora, quanto às mudanças de narrativas de Larissa, ressaltando o caráter constitutivo da linguagem assim como as narrativas sobre as instituições; nas situações a seguir podemos descrever as narrativas dominantes sendo desafiadas, trazendo novas possibilidades de ação.

Durante os três anos iniciais em que Larissa frequentou o CAPS eu compartilhava com a equipe algumas descrições sobre ela, tais como, "uma pessoa exigente e muito difícil de relacionar, que apresentava pouca resistência à frustração". Esse discurso dominante da equipe não permitia que novos sentidos perpassassem a imagem que tínhamos de Larissa. O comportamento que na época era chamado de difícil atualmente é ressignificado por mim, hoje, como persistente, descrevendo Larissa, como uma pessoa determinada que é, não abandona aquilo que quer, que apresenta grande capacidade de suportar frustrações, visto que já havia sido internada cerca de quarenta vezes e não se conformava em ficar institucionalizada. Quais realidades são possíveis de ser construídas quando abandonamos o discurso dominante? Quais realidades sociais construímos quando descrevemos uma pessoa como difícil e exigente? E como persistente? São realidades muito diferentes que, quando compartilhadas, produzem consequências distintas. Retomando novamente as discussões de Bakhtin (2011) a respeito da atividade estética, podemos dizer que tam- 
${ }^{4} 0$ mesmo pode ser dito sobre Larissa em relação à equipe, ao perceber novos aspectos do processo em que se encontrava a cliente, 0 que pode ressignificar o trabalho do qual participava, dando aos terapeutas uma visão de seus atos que Ihes eram inacessíveis. Larissa ocupava um lugar único nessa relação, ou seja, tinha a capacidade de um excedente de visão que apenas ela enxergava e que possibilitou transformações no trabalho do CAPS.

5 "El revertir la luz y el sonido le daba uma libertad sorprendente a la relación entre nosotros y la familia.

Ya no érmos los únicos responsables, sólo eramos uma de las dos partes" (Andersen, 1994, p. 34). bém, nessa relação, as possibilidades de completude e acabamento foram transformadas; inicialmente a visão de "pessoa difícil" permitia apenas a reafirmação dos discursos com os quais Larissa viveu durante toda sua vida, entretanto, ao perceber novos aspectos de seu horizonte social e também de suas qualidades, a equipe pôde lhe retornar uma nova imagem externa, inacessível à cliente 4 .

Da mesma forma, quando recebo o telefonema solicitando uma conduta, a partir do seu questionamento, entro contato com inúmeras vozes sociais de desabrigados, das injustiças sociais, das desigualdades, da miséria que despertam em mim sentimentos que, devido à naturalização dessa problemática em nosso cotidiano da saúde, acabam ficando adormecidos. Respondo dialogicamente ao seu grito de reivindicação aos seus direitos tomando a decisão de ir ao hospital. Poder descrevê-la como uma pessoa desabrigada, desafiando o discurso dominante dos inúmeros diagnósticos, ajuda a construir o lugar de uma pessoa que necessita de moradia, e não apenas de medicamentos.

No caso da Larissa, podemos pensar na ampliação da sua história e o trabalho em conjunto: a equipe reflexiva a permitiu sair da história dominante "de alguém que não dá conta da própria vida e precisa ser cuidada" para uma posição mais ativa, ao valorizar as pequenas coisas que ela dava conta de fazer. Ajudou também a desconstruir o discurso dominante de que "ninguém se importava com ela", que tanto fazia onde ela iria ser "tacada", para a valorização da sua voz e da sua importância, à medida que ela conseguiu mobilizar duas equipes diferentes para pensar juntas, além de conseguir que uma das participantes, sensibilizada pela sua dor, se dispusesse a cuidar de seu dinheiro enquanto Larissa não conseguisse fazê-lo.

Larissa inicia com seu questionamento um movimento de quebra dos muros das instituições, indagando, de certa forma, nossa maneira isolada de trabalhar e propondo para as equipes novos modos possíveis. Provoca uma ruptura com a cultura dominante de que a instituição sabe qual a melhor maneira de cuidar de uma pessoa, sabe o que é melhor para a vida do outro. Sai neste momento de uma posição passiva para uma posição de luta pelos seus direitos e ativa para sua vida. Retomo novamente Tom Andersen $(1994)^{5}$ que, ao narrar a construção da equipe reflexiva e romper, mesmo que não totalmente, as barreiras que separavam a equipe da família, sentiu-se surpreendido pela liberdade que esta mudança provocou nas relações. Ao inverter o som e a luz a equipe já não era a única responsável pelos cuidados, apenas uma das partes.

O grito de socorro de Larissa, trancada dentro de uma instituição, produz ecos em minhas dúvidas sobre as maneiras como exercemos o ato de cuidar e traz à tona meus diálogos internos de que o cuidado deve ser uma construção conjunta. Ao introduzir os processos reflexivos na conversa entre Larissa e as duas equipes de cuidado em um hospital psiquiátrico, além de colocarmos em prática um dos maiores lemas ainda muito desrespeitado da Reforma Psiquiátrica - "nada sobre mim, sem mim" - também são propostas novas maneiras de estabelecer conversas entre as equipes, fornecendo oportunidades para a construção de novas narrativas sobre o adoecer e cuidado.

Esta história é um modo de expor a grande fratura existente em nossas instituições inseridas em uma hierarquia burocrática de poder que não 
leva em conta a voz daquele que está sendo cuidado. Faz-me pensar em quantas Larissas são institucionalizadas todos os dias sem a prerrogativa de gritar pelos seus direitos ou, mesmo gritando, serem silenciadas pelas nossas instituições. Há necessidade urgente de ações sociais que busquem promover o protagonismo e a inclusão dos usuários da saúde mental desafiando o discurso dominante de que é possível saber sobre o outro mais do que ele mesmo e desenvolver mais práticas conjuntas de cuidado.

Considero a vivência de recontar o caso de Larissa como um grande marco em minha vida profissional como psiquiatra, terapeuta familiar e gestora de uma unidade de saúde mental. Como psiquiatra, essa vivência deixa bem clara a necessidade de olharmos para nosso cliente muito além do diagnóstico, principalmente em casos tão crônicos em que a internação parece ser o único recurso. Como terapeuta familiar, posso falar do quanto a voz de Tom Andersen ainda permeia a minha prática, para muito além de um cuidado familiar. Como gestora, ainda trago a voz da irreverência, da curiosidade e da quebra dos protocolos como uma grande possibilidade de ajuda em vários contextos na saúde mental. Penso que Larissa nos ensina uma grande lição sobre possibilidades e luta e sou muito grata por tê-la conhecido.

\section{REFERÊNCIAS}

Amorim, M. (2012). Cronotopo e exotopia. In B. Brait (Org.), Bakhtin Outros conceitos-chave (pp. 95-114), São Paulo: Contextos.

Andersen, T. (1994). El equipo reflexivo: diálogos y diálogos sobre los diálogos. Barcelona: Gedisa.
Andersen, T: (1998). Reflexões sobre as reflexões com as famílias. In S. McNamee \& K. J. Gergen (Orgs.), A terapia como construção social (pp. 69-83). Porto Alegre: Artes Médicas.

Andersen, T.(1999). Processos reflexivos (R. M. Bergallo,Trad.). Rio de Janeiro: Noos/ITF-RJ.

Andersen, T. (2004). A linguagem não é inocente. Nova Perspectiva Sistemica, 23,19-26.

Anderson, H. \& Goolishian, H. (1998). O cliente é o especialista: a abordagem terapêutica do não-saber. In S. McNamee \& K. Gergen (Orgs.), A terapia como construção social (pp. 3450). Porto Alegre: Artes Médicas.

Bakhtin, M. (2011). Estética da criação verbal. São Paulo: Martins Fontes.

Barros, D. L. P. (1999). Dialogismo, polifonia e enunciação. In J. L. Fiorin (Org.), Dialogismo, polifonia, intertextualidade (pp. 1-9). São Paulo: Edusp.

Cecchin, G. (1987). Hypothesizing, circularity, and neutrality revisited: an invitation to curiosity. Family Process, 26(4), 405-413.

Cecchin, G. (1998). Construindo possibilidades terapêuticas In S. McNamee \& K. Gergen (Orgs.), A terapia como construção social (pp. 106116). Porto Alegre: Artes Médicas.

Gergen, K. J. (2010). Saúde mental e deterioração cultural. Nova Perspectiva Sistêmica, 36, 9-27.

Kaplan, H. I. \& Sadock, B. J. (1990). Compendio de psiquiatria. Porto Alegre: Artes Médicas.

Nunes, J. M. S., Guimarães, J. M. X.s \& Sampaio, J. J. C. (2016). A produção docuidadoem saúde mental:avanços e desafios à implantação do modelo de atenção psicossocial territorial. Physis, 26(4), 1213-1232. Recuperado de http://www.scielo.br/scielo. php? script $=$ sci arttext\&pid $=$ S0103- 


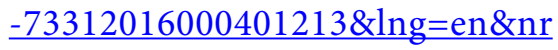
$\underline{m=i s o}$.

Rasera, E. F. \& Japur, M. (2007). Grupo como construção social: aproximações entre construcionismo social e terapia de grupo. São Paulo: Vetor.

Yasui, S. (2006). Rupturas e encontros: desafios da Reforma Psiquiátrica Brasileira, Rio de Janeiro. Recuperado de https://www.arca.fiocruz.br/ bitstream/icict/4426/2/240.pdf

White, M. \& Epston, D. (1990). Narrative means to therapeutic ends. New York: Norton.

White, M. (2012). Mapas da prática narrativa. Porto Alegre: Pacartes.

\section{ROSÂNGELA RUSSO}

Médica Psiquiatra pela Faculdade de Medicina de Ribeirão Preto - USP. Terapeuta Família/ Casal pelo Instituto Familiae-Ribeirão Preto-SP. Docente do Instituto ConversAções Ribeirão Preto - SP.

E-mail: rrusso2910@gmail.com 